\title{
Analisis Manajemen Risiko Lingkungan, Sosial dan Tata Kelola pada Usaha Budidaya dan Pengolahan Kelapa Sawit (Studi Kasus: PT PP London Sumatra Tbk)
}

\section{Analysis of Environmental, Social and Governance (ESG) Risk Managements to the Cultivation and Processing of Palm Oil (Case Studi London Sumatra Ltd)}

Tria Mutiari Meilan', Sapta Raharja ${ }^{2}$, dan Muhammad Syamsun ${ }^{3}$

${ }^{1}$ Program Magister Pengembangan Industri Kecil Menengah, Sekolah Pascasarjana IPB

${ }^{2}$ Departemen Teknologi Industri Pertanian Fateta IPB

${ }^{3}$ Departemen Manajemen FEM IPB

\begin{abstract}
ABSTRAK
Kelapa sawit (Elaeis guineensis Jacq.) merupakan salah satu komoditas perkebunan andalan di Indonesia. Kelapa sawit dapat diolah menjadi minyak sawit yang dikenal sebagai Crude Palm Oil (CPO) dan Palm Kernel Oil (PKO). Produksi CPO dan PKO di Indonesia mengalami peningkatan yang signifikan beberapa tahun terakhir. Industri kelapa sawit sering dituding menyebabkan kerusakan lingkungan karena beberapa praktek budidaya dan pengolahan yang ditenggarai menyebabkan kandungan emisi gas rumah kaca. Pemerintah telah menerapkan kewajiban sertifikasi Indonesia Sustainable Palm Oil (ISPO) sesuai dengan komitmen pemerintah Indonesia untuk memperbaiki keberlanjutan industri kelapa sawit Indonesia. Tujuan penelitian ini adalah (1) mengidentifikasi dan menganalisa dampak risiko terhadap lingkungan, sosial dan tata kelola (LST) pada budidaya dan pengolahan kelapa sawit; (2) mengidentifikasi dan menganalisa tingkat kesiapan pemenuhan persyaratan ISPO; (3). menentukan rekomendasi pengendalian risiko (risk control). Metode yang digunakan adalah deskriptif dan semi kuatitatif yang bersifat studi kasus. Risiko ekstrim terdapat pada tahap persiapan areal lahan. Pengendalian risiko yaitu risk avoidance. Nilai kesiapan ISPO pada Arta Kencana estate sebesar 8.86, angka tersebut menunjukan bahwa meski Arta Kencana estate belum tersertifikasi ISPO namun telah menerapkan prinsip-prinsip berkelanjutan. Kebun Arta Kencana perlu melengkapi dan melakukan penyempurnaan administrasi dan dokumen persyaratan untuk dapat memenuhi gap tersebut.
\end{abstract}

Kata kunci: Kelapa Sawit, manajemen risiko, prinsip ISPO, risiko LST

\section{ABSTRACT}

Palm oil (Elaeis guineensis Jacq.) is one of the main commodities in Indonesia . The production of Crude Palm Oil (CPO) and Palm Kernel Oil (PKO) in Indonesia has increased significantly in recent years. The palm oil industry is often accused of causing environmental degradation because some of the cultivation and processing practices are suspected to cause greenhouse gas emissions. The Government has implemented the obligations of certification of Indonesia Sustainable Palm Oil (ISPO) in accordance with the Government of Indonesia's commitment to improve the sustainability of the Indonesian palm oil industry. The objectives of this research are (1) To identify and analyze the impact of risk on environment, social and governance (ESG Risk) at each stage of oil palm cultivation and processing. (2) To identify and analyze the level of readiness to fulfill ISPO requirements (3). Determine the recommendations of risk control in the cultivation and processing of oil palm. The method used in this research is descriptive and analytic method which is a case study. Results of analysis at PT. London Sumatra (Lonsum) especially at Arta Kencana Estate, Lahat, South Sumatera which was not ISPO Certified yet, shows that there are 16 ESG risks and the highest is related to the preparation stage of the land area. Risk control recommended is Risk Avoidance. Arta Kencana Estate in general have fulfilled

\footnotetext{
*) Korespondensi:

Jl.Bangkirai Blok F no.4 Komplek Budi Agung, Sukadamai, Tanah Sereal, Bogor; email: triamtr@gmail.com
} 
almost all of the requirements for compliance with required principles with an average index of 8.86 . Arta Kencana Estate are need to complete and perform administrative improvements and requirements documents to be able to meet the gap. In this study found that the ESG risk on palm oil can be mitigated through the fulfillment of ISPO principles.

Key words: ESG risk, ISPO principles, palm oil, risk management

\section{PENDAHULUAN}

Kelapa sawit (Elaeis guineensis Jacq.) merupakan salah satu komoditas perkebunan andalan di Indonesia. Agribisnis kelapa sawit adalah salah satu dari sedikit industri yang merupakan keunggulan kompetitif indo nesia untuk bersaing di tingkat global (Pahan, 2007). Kelapa sawit (Elaeis guineensis Jacq.) merupakan salah satu komoditas perkebunan andalan di Indonesia. Agribisnis kelapa sawit adalah salah satu dari sedikit industri yang merupakan keunggulan kompetitif indonesia untuk bersaing di tingkat global (Pahan, 2007). Kelapa sawit dapat diolah menjadi minyak sawit yang dikenal sebagai Crude Palm Oil (CPO) dan Palm Kernel Oil (PKO).

Produksi CPO dan PKO di Indonesia mengalami peningkatan yang signifikan pada lima tahun terakhir. Produksi CPO pada tahun 2015 mengalami peningkatan menjadi 31.284.306 ton dari 21.958.120 ton pada tahun 2010 dan produksi PKO mengalami peningkatan menjadi 6.256.861 ton dari 4.391.624 ton pada tahun 2010 (Dirjenbun, 2015).

Peningkatan jumlah produksi minyak kelapa sawit tidak terlepas dari peningkatan luas areal perkebunan yang ada. Luas areal perkebunan kelapa sawit di Indonesia selama beberapa tahun terakhir ini mengalami peningkatan yang cukup besar. Tahun 2010 luas areal perkebunan kelapa sawit sebesar 8.385.394 ha dan pada tahun 2015 menjadi 11.300.370 ha (Dirjenbun, 2015).

Teknik budidaya kelapa sawit terdiri dari beberapa tahapan diantaranya pembibitan, penanaman bibit, pemeliharaan, pemanenan dan pengolahan tandan buah segar (TBS). Proses pengolahan TBS di pabrik juga terdiri atas beberapa tahapan. Hal yang paling penting dari pemprosesan TBS adalah pemanfaatan limbah TBS. Apabila pemanfaatan limbah tidak dikelola dengan baik akan terjadi pencemaran lingkungan yang berpengaruh terhadap iklim dan kerusakan lainnya (Saputra et al., 2007)

Indonesia mempunyai 22,5 juta hektar lahan gambut atau sekitar 12 persen dari seluruh lahan kelapa sawit. Pengeringan dari persediaan karbon yang sangat banyak ini dan perubahan menjadi lahan kelapa sawit memberikan kontribusi kepada emisi yang sangat luas dari rumah kaca dan memberikan kontribusi kepada masalah mutu udara musiman. Belakangan ini kelapa sawit Indonesia terus digempur kampanye hitam dengan isu berkelanjutan. Greenpeace mengklaim 20\% dari GHG Global disebabkan oleh deforestasi. Perkebunan kelapa sawit dianggap industri paling merusak hutan hujan tropis di Indonesia. Dalam 2 dekade belakangan ini Nature Alert mengklaim hanya tersisa sedikit. (Dradjat, 2012). Kata Lingkungan, Sosial dan Tata Kelola (LST) berasal dari Environmental, Social and Governance (ESG) adalah terminologi dan konsep yang pertama kali diusulkan oleh inisiatif "Who Cares Wins" dari United Nation Global Compact (Perjanjian Global Perserikatan Bangsa-bangsa) pada Juni 2004 yang bertujuan untuk memfokuskan para mayoritas investor dan analis keuangan terhadap prinsip pelaporan keuangan terkait isu dan interaksi antara isu-isu LST (OJK, 2015).

Kementerian Pertanian RI telah menerbitkan Peraturan Menteri Pertanian Nomor 11 tahun 2015 tentang Sistem Sertifikasi Kelapa Sawit Berkelanjutan Indonesia (Indonesian Sustainable Palm Oil/ISPO) bagi Perusahaan kelapa sawit di wilayah Indonesia. Ketentuan ini berlaku wajib (mandatory) bagi perusahaan perkebunan tapi sukarela (voluntary) bagi usaha pekebun kecil. Apabila perusahaan kelapa sawit melakukan pengelolaan perkebunan kelapa sawit sesuai dengan prinsip ISPO maka risiko LST pada budidaya dan pengolahan kelapa sawit diperkirakan akan termitigasi.

Tujuan penelitian adalah (1) Mengidentifikasi dan menganalisa dampak risiko LST pada setiap tahapan budidaya dan pengolahan kelapa sawit oleh PT. PP London Sumatra Tbk (Lonsum); (2) Mengidentifikasi dan menganalisa tingkat kesiapan pemenuhan persyaratan ISPO dan manajemen risiko yang dilakukan; dan (3) Menentukan rekomendasi pengendalian risiko (risk control) dalam budidaya dan pengolahan di Lonsum. 


\section{METODE PENELITIAN}

Penelitian dilaksanakan pada bulan Agustus-November Tahun 2017, bertempat di Jakarta, Palembang dan Lahat. Dilakukan penelitian pada Kebun Arta Kencana Estate karena kebun tersebut merupakan salah satu kebun milik Lonsum yang belum tersertifikasi ISPO.

Tahap awal dalam penelitian dengan mempelajari proses kerja perusahaan untuk memperoleh pemahaman terhadap seluruh tahapan budidaya dan pengolahan kelapa sawit untuk dapat mengidentifikasi risikonya

\section{Pengumpulan data}

Tahap pengumpulan data dari data sekunder maupun primer hasil wawancara dan kuesioner dilakukan dengan analisis deskriptif untuk mendapatkan informasi lebih mendalam tentang objek penelitian (Rangkuti, 2006). Penelitian ini menggabungkan jenis data primer dan data sekunder. Dilakukan observasi lapangan terhadap 8 orang narasumber di Jakarta, Palembang dan Lahat khususnya Arta Kencana Estate secara on site dan offsite.

\section{Pengolahan Data dan Analisis}

Pengolahan dan analisis data meliputi:

1. Analisis kualitatif, dimana data yang telah terkumpul dideskripsikan atau digambarkan sebagaimana adanya. Identifikasi risiko dilakukan untuk setiap tahapan budidaya dan pengolahan.

2. Analisis kuantitatif, bertujuan untuk melakukan pengukuran terhadap tingkat risiko LST yang telah teridentifikasi. Pengukuran risiko operasional diukur berdasarkan faktor yaitu risiko yang melekat pada suatu aktivitas (inherent risk) dan sistem pengendalian risiko (risk control system) (IBI, 2012). Pengukuran risiko dilakukan dengan menghitung faktor likelihood dan impact dengan skala nilai masingmasing faktor sebagaimana Tabel 1.
Tabel 1. Perhitungan nilai likelihood (probabilitas) dan impact (dampak)

\begin{tabular}{|c|c|c|}
\hline Nilai & Likelihood & Impact \\
\hline 5 & hampir pasti & kerugian sangat besar \\
\hline 4 & $\begin{array}{l}\text { kemungkinan besar } \\
\text { bakal terjadi }\end{array}$ & kerugian besar \\
\hline 3 & $\begin{array}{l}\text { kemungkinan dapat } \\
\text { terjadi }\end{array}$ & kerugian sedang \\
\hline 2 & $\begin{array}{l}\text { kemungkinan kecil } \\
\text { terjadi }\end{array}$ & kerugian kecil \\
\hline 1 & jarang terjadi & dapat diabaikan \\
\hline
\end{tabular}

Inherent risk adalah hasil perkalian antara likelihood dan impact. Inherent Risk dikurangi nilai efektifitas kontrol menjadi nilai residual risk. Efektifitas kontrol menunjukan bagaimana penerapan dari mitigasi risiko yang telah ditetapkan oleh Perusahaan dilakukan secara konsisten. Perhitungan efektifitas kontrol dilakukan sesuai skala pada Tabel 2.

Matriks pemetaan nilai risiko dibuat dengan membuat peta risiko atau heatmap, baik sebelum dan sesudah sesudah kontrol eksisting sebagaimana Gambar 1. Gap analisis ISPO dilakukan dengan mempelajari dokumen-dokumen terkait yang diperoleh. Pengukuran indeks pemenuhan ISPO dilakukan dengan menilai persentase pemenuhan terhadap 7 prinsip ISPO dan kemudian dihitung nilai rata-rata sebagai nilai akhir kesiapan ISPO dengan skala antara nol sampai sepuluh.

\section{HASIL DAN PEMBAHASAN}

Risks atau risiko bagi usaha dunia pada umumnya bersumber dari terdapatnya ketidakpastian (Uncertainties) yang menyebabkan tertekannya profitability atau bahkan dapat menimbulkan kerugian (Masyhud, 2006). Pengelolaan kelapa sawit yang buruk menyebabkan berbagai risiko "The continued development of palm oil under poor or corrupt governance systems not only impacts important animal species but also displaces indigenous populations from their land, causes tropical forest fires, and leads to severe social conflicts" (WWF, 2012).

Tabel 2. Penetapan nilai efektifitas kontrol

\begin{tabular}{cll}
\hline \multicolumn{1}{c}{ Nilai } & \multicolumn{1}{c}{ Penerapan kontrol } & \multicolumn{1}{c}{ Perhitungan } \\
\hline $100 \%$ & $\begin{array}{l}\text { Telah dilakukan di seluruh aspek secara } \\
\text { konsisten }\end{array}$ & $\begin{array}{l}\text { Mengurangi 1 (satu) nilai likelihood } \\
\text { dan 1 (satu) nilai impact } \\
\text { Telah dilakukan secara konsisten namun } \\
\text { Mengurangi 1 (satu) nilai likelihood }\end{array}$ \\
& $\begin{array}{l}\text { belum seluruh aspek } \\
\text { Belum dilakukan untuk seluruh aspek dan } \\
\text { belum secara konsisten }\end{array}$ & $\begin{array}{l}\text { Tidak mengurangi nilai likelihood/ } \\
\text { impact }\end{array}$ \\
\hline
\end{tabular}




\begin{tabular}{|c|c|c|c|c|c|c|}
\hline & \multicolumn{7}{|c|}{ Impact } \\
\cline { 2 - 7 } & & 1 & 2 & 3 & 4 & 5 \\
\hline & 5 & Sedang & Tinggi & Tinggi & Ekstrim & Ekstrim \\
\hline \multirow{2}{*}{} & 4 & Sedang & Sedang & Tinggi & Tinggi & Ekstrim \\
\hline \multirow{2}{*}{} & 3 & Rendah & Sedang & Sedang & Tinggi & Ekstrim \\
\cline { 2 - 7 } & 2 & Rendah & Sedang & Sedang & Tinggi & Tinggi \\
\hline & 1 & Rendah & Rendah & Sedang & Sedang & Tinggi \\
\hline
\end{tabular}

Gambar 1. Pemetaan risiko sesuai nilai likelihood dan impact

Identifikasi terhadap risiko LST dimulai dari tahapan persiapan areal lahan (R1-R4), pembibitan (R.5), pemeliharaan tanaman (R.6R.8), pemanenan (R.9), pengangkutan TBS (R.10), pengolahan (R.11-R.13), pengendalian limbah (R.14) dan pengelolaan tenaga kerja (R.15-R.16). Risiko LST tertinggi terdapat pada tahapan persiapan areal perkebunan R.1-R.4).

Arta Kencana Estate merupakan konversi dari hutan produktif dan hutan primer yang dimiliki penduduk lokal sejak tahun 1995. Kondisi kebun bukan merupakan lahan gambut dan berada pada permukaan yang tidak rata/berbukit. Lahan berada di lingkungan masyarakat suku Lahat dan suku Kikim. Manajemen Lonsum menyadari bahwa masalah agraria lahan sekarang menjadi isu yang sensitif dan akan berdampak besar bila menyebabkan masyarakat marah, sehingga dipastikan status lahan sudah clear, tidak terdapat masalah dengan tanah adat atau ulayat. Mitigasi yang dilakukan Lonsum terhadap risiko ini meliputi proses pemilihan lahan, peninjauan status lahan dan penyelesaian status lahan yang diatur pada SOP OP 2.8. tentang Land Preparation-Strategies and Parameters.

Risiko LST kedua tertinggi adalah terkait pengendalian limbah Bahan Berbahaya dan Beracun (B3) yang tidak sesuai standar dapat mengakibatkan pencemaran lingkungan. Pengelolaan limbah yang terdapat pada proses budidaya, yaitu kemasan kosong bekas pestisida dilakukan dengan prosedur pemusnahan, dikubur atau diserahkan ke gudang kebun, sedangkan terhadap limbah cair dilakukan prosedur Land Application sesuai ijin yang diterima dari Bupati Lahat. Kapasitas produksi pabrik sebesar 45 ton/jam dan mengolah sebanyak 300 ton per hari. Mitigasi Risiko limbah pabrik terdapat pada SOP OP 5.6.1. Empty Bunch Application untuk pengolahan limbah \& SOP OP 5.6.2. Field
Application of POME Enriched Mulch untuk pemanfaatan limbah.

Tabel 3 menunjukkan hasil identifikasi dan pengukuran risiko LST dari tahap persiapan arel sampai pengelolaan tenaga kerja termasuk efektifitas kontrol. Risiko LST ketiga yaitu terkait pengelolaan ketenagakerjaan, jumlah tenaga kerja di Arta Kencana Estate saat ini mencapai 540 orang. Risiko ketenagakerjaan pertama yaitu terjadinya kondisi pekerja yang buruk antara lain upah dibawah minimum, diskriminasi gender, dan akses yang terbatas terhadap pelayanan kesehatan dan pendidikan. Ketentuan ketenagakerjaan di Lonsum ditetapkan oleh Departemen Human Resorces Development (HRD) kantor pusat yang berlokasi di Jakarta. Lonsum memperhatikan ketentuan ketenagakerjaan dalam pelayanan kesehatan, safety dan SMK3. Ketentuan dapat diakses oleh pekerja melalui portal internal "Mylonsum". Risiko ketenagakerjaan kedua yaitu pekerja pendatang dapat memicu konflik sosial dan diskriminasi lokal. Arta Kencana Estate berada disekitar masyarakat suku Lahat dan Kikim. Perusahaan menetapkan komposisi masyarakat lokal dan pendatang 70\%. Kehadiran Perusahaan di tengah masyarakat telah memberikan dampak positif yaitu penyerapan tenaga kerja dan peningkatan ekonomi masyara-kat. Pekerja Lonsum se-bagian besar adalah berasal dari masyarakat sekitar kebun sehingga status masyarakat sekitar tercatat full employment.

Mitigasi risiko ini dilakukan dengan strategi corporate social responsibility (CSR). Lonsum memberikan penyuluhan dan pelatihan tentang perkebunan dan pertanian kepada masyarakat sekitar agar kualitas hasil produksi tanaman meningkat dan memiliki nilai jual tinggi. Arta Kencana estate memiliki Sekolah Dasar, Taman Kanak-kanak dan Rumah Pintar sebagai tempat/sarana belajar bagi anak-anak karyawan 
Tabel 3. Identifikasi dan pengukuran risiko LST

\begin{tabular}{|c|c|c|c|c|c|c|}
\hline No & Risiko & $\begin{array}{c}\text { Likeli- } \\
\text { hood }\end{array}$ & Impact & $\begin{array}{c}\text { Inherent } \\
\text { Risk }\end{array}$ & $\begin{array}{l}\text { Efekti- } \\
\text { fitas }\end{array}$ & $\begin{array}{l}\text { Residual } \\
\text { Risk }\end{array}$ \\
\hline R.1 & $\begin{array}{l}\text { Konversi lahan dari hutan atau habitat lainnya } \\
\text { mengakibatkan perubahan iklim }\end{array}$ & 4 & 5 & 20 & $80 \%$ & 15 \\
\hline R.2 & $\begin{array}{l}\text { Konversi lahan dari hutan/habitat lainnya meng- } \\
\text { akibatkan kehilangan ekosistem, degradasi/kehilangan } \\
\text { keanekaragaman hayati }\end{array}$ & 4 & 5 & 20 & $80 \%$ & 15 \\
\hline R.3 & $\begin{array}{l}\text { Praktek pembersihan lahan dengan cara pembakaran } \\
\text { dapat mengakibatkan peningkatan } \mathrm{CO} 2 \text { yang signifikan }\end{array}$ & 4 & 5 & 20 & $80 \%$ & 15 \\
\hline R...4 & $\begin{array}{l}\text { Akuisisi lahan dan konversi hutan dengan kondisi yang } \\
\text { tidak memperhatikan hak-hak masyarakat lokal dapat } \\
\text { mengakibatkan hilangnya ekosistem untuk masyarakat } \\
\text { adat dan penduduk lokal }\end{array}$ & 4 & 5 & 20 & $80 \%$ & 15 \\
\hline R.5 & $\begin{array}{l}\text { Penggunaan bibit yang kurang tepat sehingga } \\
\text { membutuhkan penggunaan pestisida berlebih dalam } \\
\text { pemeliharaannya }\end{array}$ & 3 & 3 & 9 & $80 \%$ & 6 \\
\hline R.6 & $\begin{array}{l}\text { Penanaman di area yang tidak sesuai dapat } \\
\text { mengakibatkan erosi dan kehilangan tanah }\end{array}$ & 3 & 5 & 15 & $80 \%$ & 10 \\
\hline R.7 & $\begin{array}{l}\text { Penggunaan pestisida yang berlebih dan aplikasi } \\
\text { herbisida dapat menyebabkan meningkatnya risiko bagi } \\
\text { pekerja, ekosistem sekitar dan komunitas lokal }\end{array}$ & 4 & 3 & 12 & $80 \%$ & 9 \\
\hline R.8 & Kesalahan dalam teknik Pengelolaan Air & 3 & 4 & 12 & $80 \%$ & 8 \\
\hline R.9 & $\begin{array}{l}\text { Adanya pedagang perantara yang membeli barang dari } \\
\text { plasma secara langsung dengan harga dibawah standar }\end{array}$ & 4 & 3 & 12 & $80 \%$ & 9 \\
\hline R.10 & $\begin{array}{l}\text { Peningkatan polusi akibat kendaraan transportasi yang } \\
\text { berdampak pada kehidupan masyarakat sekitar }\end{array}$ & 4 & 3 & 12 & $80 \%$ & 9 \\
\hline R.11 & $\begin{array}{l}\text { Proses pengolahan di pabrik kelapa sawit dapat } \\
\text { menghasilkan emisi metana }\end{array}$ & 5 & 3 & 15 & $100 \%$ & 8 \\
\hline R.12 & $\begin{array}{l}\text { POME mengandung signifikan material, nitrogen dan } \\
\text { phospor yang dapat berakibat negatif kepada tanah dan } \\
\text { saluran air }\end{array}$ & 3 & 5 & 15 & $80 \%$ & 10 \\
\hline R.13 & Timbulnya polusi udara, suara/kebisingan dan getaran & 4 & 4 & 16 & $100 \%$ & 9 \\
\hline R.14 & $\begin{array}{l}\text { Pengendalian limbah B3 yang tidak sesuai praktek ter- } \\
\text { baik, sehingga mengakibatkan pencemaran lingkungan }\end{array}$ & 4 & 5 & 20 & $100 \%$ & 12 \\
\hline R.15 & $\begin{array}{l}\text { Terjadinya kondisi pekerja yang buruk antara lain akses } \\
\text { yang terbatas terhadap pelayanan kesehatan dan } \\
\text { pendidikan }\end{array}$ & 4 & 4 & 16 & $80 \%$ & 12 \\
\hline R.16 & $\begin{array}{l}\text { Pekerja pendatang memicu konflik sosial dan } \\
\text { diskriminasi lokal }\end{array}$ & 4 & 4 & 16 & $80 \%$ & 12 \\
\hline
\end{tabular}

dan masyarakat desa sekitar kebun dalam bidang pendidikan. Lonsum juga memberikan program bantuan beasiswa berupa biaya pendidikan bagi anak-anak dari keluarga masyarakat yang tidak mampu agar tetap bisa bersekolah. Lonsum memberikan bantuan untuk sekolah-sekolah di sekitar kebun berupa sumbangan/donasi untuk guru honor dan berbagai kegiatan kesehatan untuk memitigasi dampak sosial yang tinggi.

\section{Pemetaan Risiko (Heatmap)}

Terdapat 4 risiko kategori ekstrim yaitu R.1, R.2, R.3, R.4 memiliki nilai inherent risk tertinggi, yaitu 20 (nilai likelihood 4, nilai impact 5). Tahap persiapan lahan merupakan titik yang kritis dari sebuah usaha budidaya kelapa sawit karena peluang terjadinya permasalahan terkait lahan hampir pasti, baik dari sisi lingkungan maupun sosial dan berdampak kerugian sangat besar apabila lahan telah terlanjur diakuisisi, namun terjadi permasalahan yang bahkan sampai menghentikan rencana atau operasional lahan/pabrik.

Untuk kategori risiko tinggi teridentifikasi R.14 terkait pengelolaan limbah serta R.15 dan R.16 terkait pengelolaan tenaga kerja. Keenam belas jenis risiko tersebut dipetakan dalam Gambar 2, yang menunjukkan risiko yang melekat inherent risk (sebelum dikurangi dengan kontrol/mitigasi risiko) dan pemetaan residual risk (setelah dikurangi efektivitas kontrol/mitigasi risiko). 


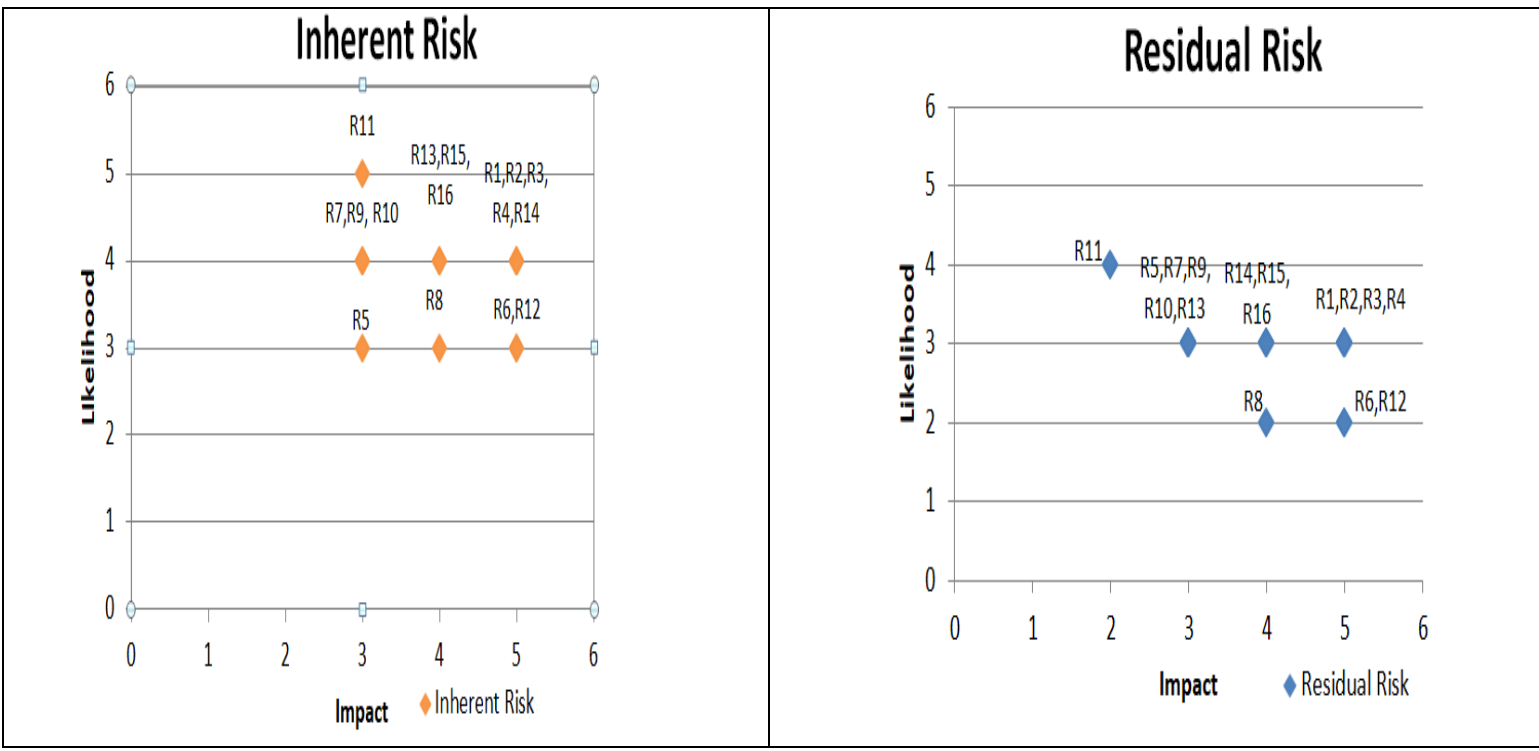

Gambar 2. Pemetaan Risiko (Heatmap)

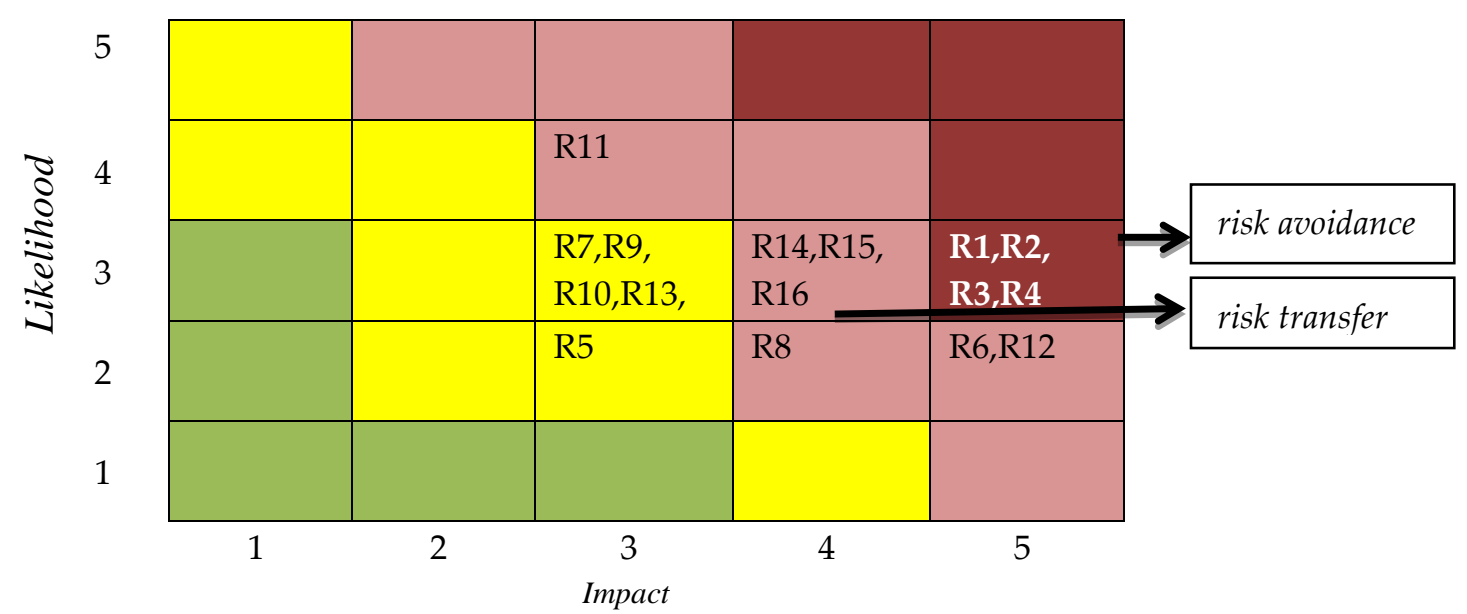

Gambar 3. Rekomendasi pengendalian risiko sesuai residual risk

Rekomendasi Pengendalian Risiko sesuai Nilai Residual Risk

Pengendalian risiko dilakukan melalui alternatif rencana aksi yang dapat dilakukan yaitu menghindarkan risiko (risk avoidance), menerima risiko (risk acceptance), mengalihkan risiko pada tempat lain (risk transfer), mitigasi risiko melalui peningkatan kualitas kontrol (IBI, 2012). Berdasarkan hasil pemetaan Gambar 2, maka ditetapkan rekomendasi pengendalian risiko yang disarankan untuk dilakukan perusahaan, yaitu sebagaimana terdapat pada Gambar 3.

Rekomendasi untuk risiko R.1, R.2, R.3 dan R.4 terkait konversi hutan/lahan yaitu mengambil pendekatan penghindaran risiko (risk avoidance). Hal ini mengingat risiko termasuk kategori ekstrim, yang apabila terjadi dapat memberikan dampak sosial dan kerugian yang besar. Calon lahan yang dalam proses survei untuk diakuisisi memiliki indikator sengketa tersebut sebaiknya manajemen mengambil keputusan untuk tidak melakukan atau membatalkan proses akuisisi maupun pengurusan HGU. Rekomendasi untuk R.14 terkait pengelolaan limbah adalah mengalihkan risiko ke pihak ketiga (outsorcing) yaitu melakukan kerjasama dengan pihak ketiga untuk pengelolaan limbah. Rekomendasi untuk R15 yaitu risk transfer ke pihak ketiga dalam bentuk asuransi kesehatan dan jiwa. Rekomendasi untuk R.16 terkait pendatang adalah risk transfer dengan melakukan kerjasama dengan pihak ketiga, antara lain: perusahaan rekrutmen dan assesment yang profesional dan independent dalam proses penerimaan pekerja dan kerjasama dengan konsultan strategi CSR untuk memastikan kegiatan CSR yang dilakukan perusahaan sesuai kebutuhan dan mampu memitigasi risiko sengketa dengan masyarakat setempat. 


\section{Gap Analysis terhadap Sertifikasi ISPO}

Berbeda dengan RSPO yang bersifat sukarela (voluntary), sebagai peraturan pemerintah Indonesia, maka ISPO berlaku wajib (mandatory) bagi perusahaan perkebunan tapi sukarela (voluntary) bagi usaha pekebun kecil. (RSPO, 2015). Gap analisis Arta Kencana estate dilakukan terhadap Prinsip dan Kriteria ISPO untuk perusahaan perkebunan yang melakukan usaha budidaya perkebunan terintegrasi dengan usaha pengolahan dan energi terbarukan (Kementan, 2015). Prinsip pertama, yang biasa disebut Stage 1 menunjukan Lonsum khususnya Arta Kencana Estate telah memenuhi seluruh aspek legalitas. Tersedia izin lokasi dari Gubernur Tingkat 1 Sumatra Selatan. Izin Lokasi tersebut peruntukannya sesuai dengan Rencana Tata Ruang Wilayah Kota (RTRW) Lahat dan Propinsi Sumatera Selatan terbukti saat dilakukan overlapping peta lokasi kebun dengan Peta "Kawasan Hutan, areal perkebunan berada di Areal Penggunaan Lain yang peruntukannya untuk pertanian. Kebun juga telah memiliki Ijin Usaha Perkebunan (SIUP). Kebun dari aspek hak atas tanah telah memiliki Hak Guna Usaha (HGU) dan Hak Guna Bangunan (HGB) untuk perkebunan tersebut. Lonsum membebaskan tanah dalam areal yang terdapat pada Izin lokasi dari hak dan kepentingan pihak lain dari kepemilikan masyarakat. Lonsum telah memfasilitasi pembangunan kebun masyarakat sekitar Lokasi Perkebunan dan saat ini mencapai 1675 petani plasma dengan luas sebesar 3.250,42 Ha. Bentuk badan hukum Lonsum adalah Perusahaan Terbatas (PT). Perusahaan telah melakukan pembangunan Kebun Masyarakat Desa (KMD) dengan luas ratarata $2 \mathrm{Ha}$ per petani. Semua kerjasama pembangunan KMD di atur dalam Surat Perjanjian Kerjasama (SPK).

Prinsip kedua, manajemen perkebunan. Lonsum memiliki perencanaan perkebunan dalam bentuk dokumen summary production report untuk 5 tahun. Produksi kelapa sawit inti per tahun 2016 sebesar 30,656,49 ton, sedangkan produksi plasma sebesar $39,717,87$ ton. Untuk menunjang pengelolaan kebun dan pabrik, Lonsum telah memiliki Standard Operating Procedure (SOP) Oil Palm (OP $01 \mathrm{~s} / \mathrm{d}$ OP 5.13) yang diakomodir dari prinsip Roundtable Sustainable Palm Oil (RSPO). Kejadian overlapping dengan areal pertambangan tidak ditemukan karena di daerah sekitar kebun tidak terdapat areal pertambangan. Rencana dan realisasi pembangunan kebun dan unit pengolah- an kelapa sawit tersedia pada dokumen di perkebunan dan dapat diakses. Penyediaan data dan informasi hal tersebut belum lengkap.

Prinsip ketiga, pelindungan terhadap pemanfaatan hutan alam primer dan lahan Gambut. Lahan Arta Kencana bukan berasal dari kawasan hutan melainkan dari perkebunan/lahan masyarakat. Arealnya tidak berada di area gambut. Lonsum telah memiliki Peta Kawasan Lindung yang berada di dalam kebun dan sekitar kebun.

Prinsip keempat, pengelolaan dan pemantauan lingkungan. Kewajiban perusahaan perkebunan yang terintegrasi dengan unit pengolahan telah tersedia. Kewajiban terkait Izin Lingkungan dan AMDAL yang disetujui oleh Dinas KLH Kab. Lahat. Pengelolaan serta limbah B3 telah diatur secara rinci pada SOP Limbah. Lonsum juga telah memiliki SOP untuk meminimalisir gangguan terkait kebisingan, getaran dan kebauan. SOP pencegahan, penanggulangan dan simulasi kebakaran dilakukan secara rutin. Dokumen pelestarian keanekaragaman hayati (biodiversity), konservasi terhadap sumber dan mutu air, kawasan lindung, konservasi kawasan dengan potensi erosi tinggi, mitigasi emisi gas rumah kaca telah tersedia. Dokumen SPK dengan vendor pengelola limbah belum tersedia dan masih perlu meningkatkan implementasi secara konsisten.

Prinsip kelima, tanggung jawab terhadap pekerja. Perusahaan memiliki dokumen panduan umum penerapan SMK3. Perusahaan memiliki dokumen kenaikan gaji yang mengacu kepada upah minimum sektoran Provinsi (UMSP). Perusahaan memiliki kebijakan tentang umur pekerja dimana perusahaan mensyaratkan bahwa umur pekerja minimal adalah 18 tahun. Perusahaan memiliki Serikat Pekerja. Perusahaan memiliki koperasi karyawan bernama Koperasi Perkasa yang telah mendapatkan Akte Pendirian dari Kepala Kantor Koperasi Pengusaha Kecil dan Menengah.

Prinsip keenam, tanggungjawab sosial dan ekonomi kepada masyarakat. Lonsum memiliki dokumen Program CSR tahunan yang disusun berdasarkan kebutuhan masyarakat melalui dokumen Sosial Impact Assesment (SIA). Sebesar lebih kurang $70 \%$ pekerja Arta Kencana merupakan penduduk setempat. Perusahaan bekerja sama dengan kontraktor lokal untuk pembuatan sarana prasarana khususnya pada awal pembangunan kebun dan pabrik. Saat ini kerjasama sebatas pembelian batu dan lebih sering menggunakan kontraktor dari kota Lahat. Dokumentasi kerjasama dengan masayarakat 
dalam bentuk Surat Perjanjian Kerja belum terdokumentasi

Prinsip ketujuh, peningkatan usaha yang berkelanjutan. Dokumen tersedia berupa tindaklanjut hasil temuan audit dan peningkatan kinerja Lonsum khususnya produksi di kebun dan pabrik. Saat ini masih terdapat dokumen tindak lanjut yang belum diarsipkan/dikelola dengan tertib.

Berdasarkan hasil perhitungan kesiapan pemenuhan prinsip ISPO berikut diperoleh nilai skor kesiapan Arta Kencana estate sebesar 8.86 (skala 0-10) sebagaimana tercermin pada diagram Gambar 4.

Rekomendasi untuk pemenuhan prinsip ISPO sebagai berikut: prinsip 2, berkoordinasi dengan manajer, kasie dan asisten agar semua dokumentasi dari aktifitas yang berhubungan dengan Principle dan Criteria (P\&C) ISPO dapat dibuat/dilengkapi. Rekomendasi prinsip 4, yaitu perusahaan harus memiliki SPK Tripartit antara perusahaan- pihak pengangkut (transportir) dan pihak pengelola, pemanfaat atau pemusnah limbah B3 (pihak ketiga). Rekomendasi prinsip 6 yaitu meningkatkan tata kelola dokumen dan pengarsipan terutama dokumen legal kerjasama dengan masyarakat. Prinsip 7 meningkatkan pemenuhan dokumen dan tindak lanjut hasil audit ISPO dilakukan sesuai target waktu.

Penerapan ISPO dapat memitigasi risiko yang teridentifikasi sebagai berikut: risiko R.1-R.4 termitigasi dengan prinsip 1, 3 dan 6. Risiko R.5R.8 termitigasi dengan prinsip kedua. Risiko R.9, R.10-R.14 terkait dengan pengelolaan limbah dan gangguan lingkungan dapat termitigasi dengan prinsip 4. Untuk R.15 dimitigasi dengan prinsip 5 dan R.16 dimitigasi dengan prinsip 6. Secara keseluruhan prinsip ISPO ke-7 dilakukan untuk memitigasi seluruh jenis risiko (R.1-R.16).

\section{KESIMPULAN}

1. Terdapat enam belas jenis risiko LST pada budidaya dan pengolahan kelapa sawit yang teridentifikasi. Residual risk ekstrim pada tahapan persiapan areal lahan dan direkomendasi dengan cara menghindarkan risiko (risk avoidance). Risiko tinggi terdapat pada tahapan pengendalian limbah dan rekomendasi untuk kerjasama untuk mengalihkan risiko ke perusahaan pengelola limbah. Risiko tinggi pengelolaan tenaga kerja direkomendasi dengan pendekatan risk transfer, yaitu bekerjasama asuransi kesehatan dan jiwa serta mitigasi konflik pendatang dilakukan dengan melakukan kerjasama dalam rekrutmen dan assessment.

2. Nilai kesiapan ISPO pada Arta Kencana estate sebesar 8,86, angka tersebut menunjukan bahwa meski Arta Kencana estate belum tersertifikasi ISPO namun telah menerapkan prinsip-prinsip berkelanjutan. Rekomendasi perbaikan penyempurnaan dokumen inter-nal dan dokumen perjanjian dengan pihak ketiga. Seluruh jenis risiko LST yang teridentifikasi dapat dimitigasi dengan pemenuhan prinsipprinsip ISPO.

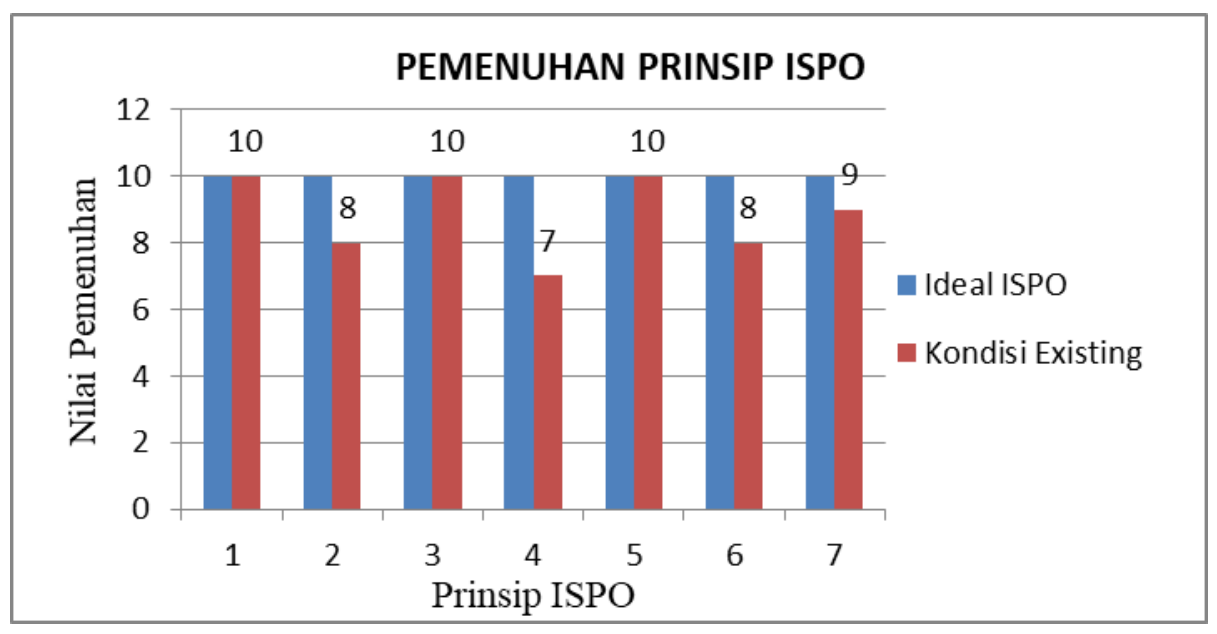

Gambar 4. Pemenuhan prinsip ISPO 


\section{DAFTAR PUSTAKA}

[Dirjenbun] Direktorat Jenderal Perkebunan. 2015. Statistik Perkebunan Indonesia 20142016 Kelapa Sawit. Jakarta (ID): Dirjenbun.

Hijriani, J., H. Sari, E.L. Mahyuni. 2015. Penerapan manajemen risiko pada pabrik kelapa sawit (PKS) IV Unit Usaha Pabatu. Jurnal Lingkungan dan Kesehatan Kerja. 6(2).

[IBI] Ikatan Bankir Indonesia. 2012. Manajemen Resiko 1: Mengidentifikasi Risiko Pasar, Operasional dan Kredit Bank. Jakarta (ID): Gramedia Pustaka Utama.

[Kementan] Kementerian Pertanian Indonesia. 2015. Peraturan Menteri Pertanian Republik Indonesia Nomor 11 Tahun 2015 tentang Sistem Sertifikasi Kelapa Sawit Berkelanjutan Indonesia (Indonesian Sustainable Palm Oil Certification System/ISPO). Jakarta (ID): Kementan.

Mashyud, A. 2006. Manajemen Resiko Strategi Perbankan dan Dunia Usaha Menghadapi Tantangan Globalisasi Bisnis. Jakarta (ID): Raja Grafindo.
[OJK] Otoritas Jasa Keuangan. 2015. Integrasi Lingkungan Sosial dan Tata Kelola bagi Bank. Jakarta (ID): OJK.

Pahan, I. 2007. Panduan Lengkap Kelapa Sawit (Manajemen Agribisnis dari Hulu hingga Hilir). Jakarta (ID): Penebar Swadaya

Rangkuti, F. 2006. Analisis SWOT: Teknik Membedah Kasus Bisnis. Jakarta (ID): Gramedia Pustaka Utama.

[RSPO] Roundtable Sustainable Palm Oil. 2017. Studi Bersama Persamaan dan Perbedaan Sistem Sertifikasi ISPO dan RSPO. [www.ispo-rspostudyindonesia.com]. [diunduh 2017 Januari 23].

Saputra, E., S. Bahri, Hs. Edward. 2007. Bio-oil dari limbah padat sawit. Jurnal Rekayasa Kimia dan Lingkungan. 6(2): 45-49.

[WWF] World Wildlife Fund for Nature. 2012. The 2050 Criteria: Guide to Responsible Investment in Agricultural, Forest and Seafood Commodities. Gland (CH). WWF. 